\title{
A Review on General Overview About Diabetes Mellitus
}

\author{
Richa Dodia, Susmita Sahoo
}

\begin{abstract}
Diabetes mellitus could also be a big issue nowadays. The approach to life and daily circumstances play the main part in this type of serious complication. Throughout this review, we get general information about the disease.
\end{abstract}

Keywords: Diabetes Mellitus, Diagnosis, Cause, Treatment.

\section{INTRODUCTION}

The term "diabetes" is obtained from the Greek word "diabainein" which indicates "to pass through' and mellitus could also be a Latin word for relating sweetness [1]. Such complications arise as a result of imbalances inside the restrictive system for storage and mobilization of metabolic fuels, nonetheless as a result of the organic process and destructive metabolism of carbohydrates, lipids, and proteins originating from defective hypoglycaemic agent secretion, hypoglycaemic agent action, or each [2]. The image of polygenic disease is polyuria-excessive urine production, polydipsia-excessive thirst, and polyphagia excessive consumption [3]. The International polygenic disease Federation estimates the general form of diabetic subjects to be 40.9 million in Asian nations and this could be more set to increase to 69.9 million through the year 2025[4].

\section{CLASSIFICATION OF DIABETES MELLITUS}

Diabetes is often classified into the subsequent general categories:

A. Type one diabetes (due to beta-cell destruction, usually resulting in absolute hypoglycaemic agent deficiency):

Type one polygenic disease is known as juvenile-onset diabetes autoimmune disorder and it's conjointly expressed as insulin-dependent diabetes mellitus [5]. It's a chronic condition during which the exocrine gland makes very little or no hypoglycaemic agent. It naturally arises in adolescence [6]. Type one is typically thought about by the presence of anti-glutamic acid decarboxylase, islet cell, or insulin antibodies, that establish T-cell mediate autoimmune disorder that results in beta-cell destruction [7].

Manuscript received on 25 November 2021 Revised Manuscript received on 04 December 2021 | Manuscript Accepted on 15 December 2021 | Manuscript published on 30 December 2021.

* Correspondence Author

Richa Virendrasinh Dodia*, Research Scholar, Department of Medical Biotechnology, V. Patel College of Pure and Applied Sciences, Charutar Vidya Mandal University, Vallabh Vidyanagar (Gujarat) India.

Dr. Susmita Sahoo, Assistant Professor, Charutar Vidhya Mandal University, Vallabh Vidyanagar, Anand (Gujarat), India.

(C) The Authors. Published by Lattice Science Publication (LSP). This is an open access article under the CC-BY-NC-ND license (http://creativecommons.org/licenses/by-nc-nd/4.0/)
Hypoglycaemic agent deficiency results in hyperglycemia and an inclination to ketoacidosis [8].

The speed of destruction of beta-cell is moderately variable; it will occur quickly in some people and slow in others [9].

Excess aldohexose levels should be able to through exogenous hypoglycaemic agent injections various times a day[10]. Type one polygenic disease occurs presents in childhood or adolescence; nonetheless, the disease will appear at all ages [11].

The precise explanation for diabetes is remaining unidentified, in most persons, there's a symptom of a response mechanism about auto-antibodies that destroy the beta islet cells [12].

B. Type two polygenic disease (due to a progressive hypoglycaemic agent bodily fluid defect on the background of hypoglycaemic agent resistance):

Type two diabetes has been remarked for an extended time as non-insulin-dependent diabetes, or adult-onset diabetes characterized by hypoglycaemic agent resistance, that may increasingly degrade to absolute resistance, however from the past, reduced beta-cell performance has been recognized as a key problem in type two diabetes [13]. Most of us through type two polygenic disease show intra-abdominal fat, which is closely related to the existence of hypoglycaemic agent resistance. what is more, high blood pressure and high lipid, and low high-density lipoprotein cholesterol levels; postprandial hyperlipemia typically is gifted in these people. this can be the foremost frequent style of diabetes and is extremely connected to a case history of polygenic disease, older age, obesity, and lack of exercise. It's most frequent in females, notable females through a history of physiological condition diabetes, and in Blacks, Hispanics, and Native Americans. [14].

C. Gestational diabetes (diabetes diagnosed within the second or trimester of physiological condition that's not visibly public diabetes):

Gestational diabetes is a good classification of distinctive females United Nations agency develops diabetes through gestation hormonal deviations contribute to the present unwellness, together with further weight and case history of polygenic disease.

Women United Nations agency develops type one diabetes throughout physiological condition and ladies with unknown while no symptoms type two diabetes that's discovered throughout the physiological condition are classified through gestational polygenic disease Mellitus [14].

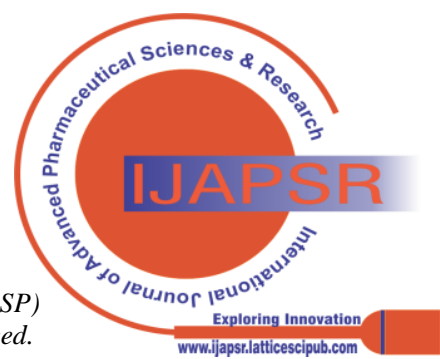




\section{Other specific kind (monogenic diabetes):}

Types of diabetes of varied legendary aetiologies are classified along to classify "Other Specific Types". This cluster includes persons with genetic defects of beta-cell perform and this form of the polygenic disease was once known as maturity-onset diabetes in youth or with defects of hypoglycaemic agent action; persons with diseases of the secretory organ exocrine gland, like inflammation or cystic fibrosis; persons with disfunction related to different endocrinopathies like acromegaly; and persons with exocrine gland dysfunction caused by drugs, chemicals or infections and that they comprise 100 percent of Diabetes mellitus cases[14].

\section{SIGNS \& CLASSIC SYMPTOMS OF DIABETES}

Considering the good nature of type 2 polygenic disorder within the early stages, the individuals must be educated on its warning signs like Unexplained weight loss, Frequent fatigue, Irritability, Repeated infections particularly within the Genital areas, Urinary tract, Skin, Oral cavity, Delayed wound healing, Dry mouth, Burning, pain, symptoms on feet, Itching, Reactive hypoglycemia, Acanthoses Nigeriansthe presence of velvety dark patches of the neck, armpit, groin that is associate degree indicator of internal secretion resistance, decreased vision, Impotence or erectile dysfunction[15]. Other, varied symptoms are ascertained because of Gluconeogenesis from amino acids and body protein, causing muscle wasting, tissue breakdown, and increase the glucose level and organic process of body fat, releasing a number of its energy and excess production of organic compound bodies [16].

\section{ICAUSES OF DIABETES}

Different causes are related to every type of polygenic disorder. In type one polygenic disorder: this kind of diabetes typically happens because of the abnormal system and destroyed internal secretion manufacturing cell within the duct gland, so internal secretion happens due to a combination of genetic and lifestyle factors. Being overweight or fat increases your risk too. So that the internal secretion doesn't maintain your blood glucose level. In physiological conditions, polygenic disorder happens throughout the maternity because of some secretion changes. The placenta manufactures a unique type of internal secretion throughout maternity and affects the internal secretion. This can cause high blood glucose throughout the pregnancy [17].

\section{ETIOLOGY OF DIABETES MELLITUS}

The word etiology comes from the Greek word "aetiologia". Hence, etiology is outlined because of the science of finding causes and origins within which disease arises. It includes a hypoglycemic agent which is the dependent type and has autoimmune etiology. Viruses like coxsackie B may additionally play a task within the etiology of polygenic disorder. Mumps and German measles Viruses like infectious disease and rubella all are shown to provide morphologic changes within the islet-cell structure. The genetic role within the etiology of polygenic disorder is controversial. Presumably, a genetic attribute makes an associate degree individual's duct gland a lot of vulnerable to one amongst the on top of viruses [18].

\section{DIAGNOSIS OF DIABETES MELLITUS}

The 1997 Yankee polygenic disorder association has a recommendation for identification of diabetes mellitus issue and target abstinence plasma aldohexose. Whereas the United Nations agency is targeting Oral aldohexose Tolerance [14] like abstinence plasma aldohexose level, plasma aldohexose, Symptoms of high blood glucose, and casual plasma aldohexose and Glycated hemoprotein (HbA1c)[19]. Diabetes mellitus is diagnosed by any of the following kinds of tests. In abstinence plasma aldohexose level ought to be eight-hour abstinence before taking this test. Condition of diabetes mellitus is $126 \mathrm{mg} / \mathrm{dl}$, more than or adequate $200 \mathrm{mg} / \mathrm{dl} 2$ hours once a 75 -gram oral aldohexose load as in a very Oral aldohexose Tolerance take a look at symptoms of high glucose and casual plasma glucose is bigger than or adequate $200 \mathrm{mg} / \mathrm{dl}$. Glycated hemoprotein (HbA1c) is bigger than or adequate $48 \mathrm{mmol} / \mathrm{mol}$ [20].

\section{TREATMENT OF DIABETES}

\section{A. Insulin and oral hypoglycemic drugs:}

Insulin medical care ought to aim to mimic nature, remarkably successful in limiting postprandial hyperglycemia and preventing symptoms between meals [21].Different preparations of internal secretion are obtainable like human insulin, beef insulin, pork insulin, insulin medical care isn't free from complications and adverse effects. The foremost vital adverse results are weight gain and symptoms once an inappropriate dose of the hypoglycemic agent is taken and once there's a mismatch between meals and internal secretion injection [22]. Necessary options of Oral symptom Agents or medication agents in diabetes mellitus may be thought-about a malady of the trendy world with an excellent impact of morbidity, mortality, and also the quality of kind of the affected individual. Diabetes mellitus may be a frequent complication of Harvery Williams Cushing syndrome that is caused by chronic exposure to Glucocorticoids by many clinical symptoms like central avoirdupois, proximal muscles weakness, hirsuteness, and neuroscience disturbance, macro-vascular complication involuntary pathology, biological process issues, dental issues, etc [23].

\section{B. Antioxidant therapy:}

A variety of antioxidants, like vitamins, supplements, plantderived active substances, and medicines with inhibitor effects, are used for aerobic stress treatment in type 2 diabetes mellitus patients. Vitamin C, fat-soluble vitamin carotene are ideal supplements against oxidative stress and its complications [24]. Inhibitor plays a vital role in lowering the chance of developing the polygenic disorder and its complications.

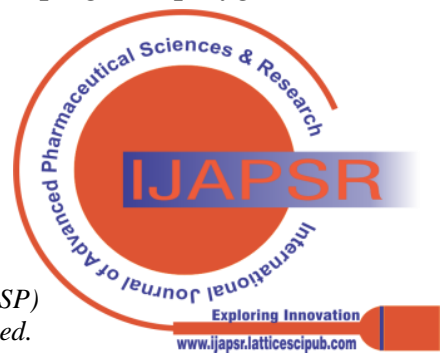




\section{Dietary Management:}

Adequate caloric value Dietary management ought to be taken properly by each diabetic and non-diabetic patient. Balanced to protein, saccharide, and fats, it's necessary to limit supermolecule intake altogether. It ought to change as closely as doable to traditional. Food intake ought to be divided into often spaced meals of comparable size and scale back total calorie intake by decreasing each fat and supermolecule. The patient should be suggested to be constant in his dietary habits from day to day [18].

\section{Herbal treatment of diabetes:}

The traditional system of medication has claimed to cure polygenic disease by exploiting the flavourer principle. Plants are typically infinite sources of active principles that may treat health problems and disorders with fewer effects. One such plant is balsam pear which belongs to the family Cucurbitaceae is used for medication [25].

\section{CONCLUSION}

Diabetes Mellitus may be a metabolic disorder characterized by the presence of chronic hyperglycemia either immunemediated which is Type 1 diabetes, insulin resistance which is Type 2, gestational, or others (environment, genetic defects, infections, and certain drugs). in line with the International polygenic disease Federation Report of 2011, 366 million people had Diabetes Mellitus, by 2030 this variety is calculable to virtually be around 552 million. There are completely different approaches to diagnose polygenic disease among people. The 1997 enzyme recommendations for the diagnosing of Diabetes mellitus concentrate on abstinence from Plasma aldohexose, whereas the United Nations agency focuses on Oral aldohexose Tolerance take a look at. This is often necessary for normal follow-up of diabetic patients with the health care supplier of significance in averting any long complications [14].

\section{REFERENCES}

1. Salman RS, Jawad AA, Al-Fartosi KG. Anti hyperglycemic effects of colostrum, virgin and multipara camel milk in alloxan-induced diabetic rats. International Journal for Sciences and Technology. 2016 Sep;143(4101):1-7.

2. Shillitoe RW. Psychology and diabetes: psycholocial factors in management and control. Chapman and Hall; 1988.

3. Sharma US, Kumar A. Anti-diabetic effect of Rubus ellipticus fruit extracts in alloxan induced diabetic rats. Journal of Diabetology. 2011 May 1;2(2):4.

4. Bacchetta R, Passerini L, Gambineri E, Dai M, Allan SE, Perroni L. et al., Defective regulatory and effector $\mathrm{T}$ cell functions in patients with FOXP3 mutations. The Journal of clinical investigation. 2006 Jun 1;116(6):1713-22. [CrossRef]

5. Cooke DW, Plotnick L. Type 1 diabetes mellitus in pediatrics. pediatr Rev. 2008 Nov 1;29(11):374-84. [CrossRef]

6. Mayfield JA. Diagnosis and classification of diabetes mellitus: new criteria. American family physician. 1998 Oct 15;58(6):1355.

7. World Health Organization. Diabetes Mellitus: Report of a WHO Study Group [meeting held in Geneva from 11 to 16 February 1985]. World Health Organization; 1985.

8. American Diabetes Association. Diagnosis and classification of diabetes mellitus. Diabetes care. 2014 Jan 1;37(Supplement 1):S8190. [CrossRef]

9. Boney CM, Verma A, Tucker R, Vohr BR. Metabolic syndrome in childhood: association with birth weight, maternal obesity, and gestational diabetes mellitus. Pediatrics. 2005 Mar 1;115(3):e290-6. [CrossRef]
10. American Diabetes Association. Standards of medical care in diabetes_-2010. Diabetes care. 2010 Jan 1;33(Supplement 1):S11-61. [CrossRef]

11. American Diabetes Association. 2. Classification and diagnosis of diabetes. Diabetes care. 2016 Jan 1;39(Supplement 1):S13-22. [CrossRef]

12. Wassmuth R, Lernmark $\AA$. The genetics of susceptibility to diabetes. Clinical immunology and immunopathology. 1989 Dec 1;53(3):358 99. [CrossRef]

13. Saisho Y. Importance of beta cell function for the treatment of type 2 diabetes. Journal of clinical medicine. 2014 Sep;3(3):923-43. [CrossRef]

14. Baynes HW. Classification, pathophysiology, diagnosis and management of diabetes mellitus. J diabetes metab. 2015 May 1;6(5):1-9.

15. Ramachandran A. Know the signs and symptoms of diabetes. The Indian journal of medical research. 2014 Nov;140(5):579.

16. Ross JS. Anatomy and physiology in health and illness. Churchill livingstone; 1987.

17. http://www.healthline.com./health/ diabetes\#sysptoms

18. Singh N, Kesherwani R, Tiwari AK, Patel DK. A review on diabetes mellitus. The Pharma Innovation. 2016 Jul 1;5(7, Part A):36.

19. Gillett MJ. International expert committee report on the role of the A1c assay in the diagnosis of diabetes: diabetes care 2009; 32 (7) 1327-1334. The Clinical Biochemist Reviews. 2009 Nov;30(4):197.

20. Eyth E, Basit H, Smith CJ. Glucose tolerance test. StatPearls [Internet]. 2019 Jun 1

21. Ciofetta M, Lalli C, Del Sindaco P, Torlone E, Pampanelli S, Mauro L. et al., Contribution of postprandial versus interprandial blood glucose to HbA1c in type 1 diabetes on physiologic intensive therapy with lispro insulin at mealtime. Diabetes Care. 1999 May 1;22(5):795-800.. [CrossRef]

22. Henry RR, Gumbiner B, Ditzler T, Wallace P, Lyon R, Glauber HS Intensive conventional insulin therapy for type II diabetes: metabolic effects during a 6-mo outpatient trial. Diabetes care. 1993 Jan 1;16(1):21-31. [CrossRef]

23. Gupta OP, Joshi MH, Dave SK. Prevalence of diabetes in India Advances in metabolic disorders. 1978 Jan 1;9:147-65.. [CrossRef]

24. Shaw JE, Zimmet PZ, De Courten M, Dowse GK, Chitson P, Gareeboo HA.et al., Impaired fasting glucose or impaired glucose tolerance. What best predicts future diabetes in Mauritius. Diabetes care. 1999 Mar 1;22(3):399-402. [CrossRef]

25. Zaman K. Medicinal plants with hypoglycemic activity. Journal of Ethnopharmacology. 1989 Jun 1;26(1):1-55. [CrossRef]

\section{AUTHOR PROFILE}

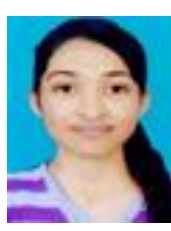

Miss Richa Virendrasinh Dodia, received his Master' in integrated biotechnology (Medical biotechnology) from Sardar Patel University, Anand, Gujarat. Currently doing Ph.D. in botany from Charutar vidya Mandal University, Anand, Gujarat.In the current study, she was involved in a review of many articles; writing and preparing a manuscript.

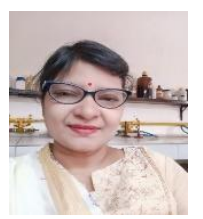

Dr. Susmita Sahoo, has received her Ph.D. in botany from IMMT (CSIR)Bhubaneswar and amp; Utkal University. She is currently a Senior Assistant Professor in Charutar Vidhya Mandal University, Vallabh Vidyanagar, Anand, Gujarat.In the current study, she was involved in the guidance of literature collection and manuscript preparation 